Original Research Paper

\title{
Combating Climate Change One Bite at a Time: Environmental Sustainability of Veganism (with a Socio- Behavioral Comparison of Vegans and Omnivores)
}

\author{
Jennifer M. Ghahari and Jennifer A. McAdam \\ Department of Sociology, William Paterson University, 300 Pompton Road Wayne, NJ, 07470 USA
}

\author{
Article history \\ Received: 03-10-2017 \\ Revised: 11-01-2018 \\ Accepted: 26-03-2018 \\ Corresponding Author: \\ Jennifer M. Ghahari \\ Department of Sociology, \\ William Paterson University, \\ 300 Pompton Road Wayne, NJ, \\ 07470 USA \\ Email: ghaharij@wpunj.edu
}

\begin{abstract}
In an era of escalating climate change, our research examines the environmental benefits of veganism and finds which factors could contribute to a societal shift towards veganism. Concentrated Animal Feeding Operations (CAFOs) release significant greenhouse gas emissions as well as expose people and animals to pathogens. Tropical rainforest destruction for grazing land, the vast amount of fresh/potable water needed for CAFOs and the exploitation of fish at unsustainable levels (impacting the greater global food chain) are all contributing to increasing climate change. Our exploratory empirical data found clear socio-behavioral differences between vegans and omnivores with regard to environmental impact. Specifically, vegans are environmentally conscious in terms of family planning (i.e. zero/negative population growth) and are also more apt to not only recycle but to seek to purchase products in recyclable packaging. Omnivores, whose behaviors drive the aforementioned debilitating effects on the climate, are amenable to altering these behaviors thereby reducing their environmental impact. Our findings indicate omnivores are open to eating vegan options and would consider adhering to a vegan lifestyle if that lifestyle positively impacts their personal health: (i.e., if their physician encouraged veganism and if legitimate reports showed animals on CAFOs were unhealthy and/or abused). Since omnivores generally do not place much importance on the environmental impact of their eating habits, a way to latently combat climate change is to increase knowledge regarding the multitude of veganism's health benefits, which should result in an increasing number of omnivores who adhere to aspects of a vegan lifestyle.
\end{abstract}

Keywords: Climate Change, Factory Farming, Greenhouse Gas Emissions, Societal Change, Veganism

\section{Introduction}

With the current environmental debate over the best way to curb greenhouse gas emissions and reduce climate change, cleaning up/lessening manufacturing emissions are usually mentioned as the foremost effective measure. However, the positive and multiscoped environmental impact of veganism has begun to gain more media attention as it is arguably the most impactful change humans can make to combat climate change. While there are several types of diet plans people can follow, our research will specifically compare the environmental effects of an omnivore lifestyle to a vegan one (arguably the most and least negatively impactful of the environment).
There are several types of diet plans people can follow, some of which include three main categories. Omnivores are "generalized feeders, with neither carnivore nor herbivore specializations for acquiring or processing food and who are capable of consuming and do consume both animal protein and vegetation" (McArdle, 1991). Vegetarians consume a "diet of foods derived from plants, with or without dairy products, eggs and/or honey" (IVU, 1985). Vegans take things a step further than vegetarians and generally don't consume any dairy, eggs or honey and adhere to "a philosophy and way of living which seeks to exclude - as far as is possible and practical - all forms of exploitation of and cruelty to, animals for food, clothing or any other purpose" (TA, 2017). 
Our study will explore the environmental consequences of carnivore consumption and further seek out the sustainability of veganism, with an understanding of what might prompt more people to consider adopting a vegan lifestyle, thusly help preserve the environment and lessen the effects of climate change.

\section{CAFO - Environmental Degradation: Disease and Emissions}

With the vast majority of the U.S. population being comprised of omnivores and the population of the country at over 324 million people (USBC, 2017) the current demand for meat can only be met through large, commercial farms. Considering the rate of global population growth $(2.5$ billion in 1950 nearly tripling to 6.9 billion in 2010) and with most developed countries having transitioned to livestock-based diets (typical of Western diets), the amount of meat needed to feed and sustain these populations is immense (UNFAO, 2012). Moreover, the UN projects meat production to more than double from 2005/2007 to 2080 (from 258 million tons to 524 million tons, annually) (UNFAO, 2006). MacDonald and McBride found that meat production has shifted from smaller, family-owned farms to larger ones - primarily with corporate contracts - and that these modern, efficient farms usually consist of single-species buildings or open-air pens (MacDonald and McBride, 2009). New technologies have led to improvements in: More effective animal breeding, more efficient machinery to process/break down the animals into usable products and specially-formulated animal feeds and livestock pharmaceuticals. These improvements have made the efficiency of these farms explode - not only in terms of focusing on one species to produce, but in terms of sheer quantity: In the past 50 years, milk production doubled, meat production tripled and egg production quadrupled (PCIAFP, 2009).

While there are several economic benefits of a factory farm, or "Concentrated Animal Feeding Operation" (CAFO) (such as low-cost sources of meat, milk and eggs as well as increased employment and increased tax expenditures/funds for schools and infrastructure) the environmental impact cannot be ignored. The Centers for Disease Control (CDC) states the most pressing public health issues associated with these farms stem from the amount of manure they produce. And it's not "just manure." Manure from largescale factory farms contains a variety of potential contaminants such as: Nitrogen and phosphorus, pathogens, growth hormones, antibiotics, chemicals used as additives to the manure or to clean equipment, animal blood, silage leachate from corn feed, or copper sulfate used in footbaths for cows (to treat lameness stemming from footrot) (Hribar, 2010).
The Government Accountability Office (GAO) found that, depending on the type and number of animals on the farm, manure production can range between 2,800 tons and 1.6 million tons a year and that large farms can produce more waste than some U.S. cities - just one CAFO with 800,000 pigs can produce over 1.6 million tons of waste a year (1.5 times more than the annual sanitary waste produced by the city of Philadelphia, Pennsylvania) (GAO, 2008). When considering the full scope of waste produced annually, it is estimated that livestock animals in the U.S. produce between 3-20 times more manure than people in the U.S. produce (or as much as $1.2-1.37$ billion tons of waste) (Rogers and Haines, 2017). Moreover, as cattle (used for both dairy and meat) have been put on high protein diets to promote faster growth/production turn around, an environmental downside to this method of rapid weight growth is the increase of methane emissions of twice that of pasture-fed cattle USDOE, 1998. Perhaps most alarming and concerning is that the CDC points out, while sewage treatment plants are required for human waste, no such treatment facility exists for livestock waste (Hribar, 2010).

While some manure is used by the farming industry, the amounts produced by CAFOs are far too much and problematic. One way to disperse the manure is to implement the low-cost method of "ground application" of untreated manure. However, manure cannot be applied while the ground is frozen and the soil can only handle so much manure (Burkholder et al., 2007). Manure can also be stored in: Deep pits under the buildings that hold animals, in clay or concrete pits, treatment lagoons, or holding ponds. But, consider the environmental implications that happen if/when these storage pits and ponds crack or leak - or when excessive ground applications cause the soil to be oversaturated with manure. The transmission of the waste into groundwater and other water sources (i.e. streams, lakes, reservoirs) lead to an abundance of micronutrients, like nitrogen and phosphorous, in the water system (Hribar, 2010). As nitrogen and phosphorous build up in water systems, water quality deteriorates in terms of hypoxia (reduced oxygen), anoxia (absence of oxygen) and toxicity. The result of this process (termed eutrophication) results in habitat loss and declines in, or complete eradication of, species' populations in those areas (Paer, 1999).

In 2000, the EPA's National Water Quality Inventory found that, "29 states specifically identified animal feeding operations as contributing to water quality impairment," (USCRS, 2010 as cited in Hribar, 2010:3). More than half of the population is estimated to rely on groundwater as its major source of drinking water in the United States, with the rate much higher in rural areas (Hribar, 2010). With groundwater more difficult to monitor than surface water, contamination levels of drinking water 
for more than half the country can actively be a health risk. Considering that groundwater can move laterally and eventually enter surface water, the potential for contamination spread exists (Spellman and Whiting, 2007).

Manure from CAFOs is a primary source of over 150 pathogens - some of which are debilitating and lifethreatening. The CDC reports that while healthy people (who are exposed to pathogens) can generally recover quickly, "those who have weakened immune systems are at increased risk for severe illness or death. Those at higher risk include infants or young children, pregnant women, the elderly and those who are immunosuppressed, HIV positive, or have had chemotherapy. This risk group now roughly compromises $20 \%$ of the U.S. population." Moreover, the risk of being infected by a pathogen is fairly high, with sources of infection including fecal-oral transmission, inhalation, drinking water, or incidental water consumption during recreational water activities (Hribar, 2010:9).

Manure produced from CAFOs is also problematic in two other regards: Emissions released as the manure breaks down; and manure particulate release (into the air) by the movement of animals. The CDC found that "Emissions caused by land application occur in two phases: One immediately following land application and one that occurs later and over a longer period as substances in the soil break down" (Hribar, 2010:5). The amount of emissions produced by a single farm is staggering. A study by Iowa State University, resulting from a lawsuit settlement between the Sierra Club and Tyson Chicken, found that just two chicken houses in western Kentucky emitted over 10 tons of ammonia in the year they were monitored (Burns et al., 2007). And in 2006, Steinfeld et al. (2006) calculated contributions to global greenhouse gas emissions and determined the animal agricultural sector surpassed those of the transportation sector, with " $18 \%$ of human-induced greenhouse gas emissions coming from the animal agricultural sector" (Steinfeld et al., 2006:xxi). Thusly, the Food and Agriculture Organization of the United Nations (FAO) highlighted the substantial role of the farm animal production sector, identifying it as "a major threat to the environment" (FAO, 2006).

Such emissions affect both workers on the farms as well as those living in neighboring communities. Children in neighboring areas of a factory farm have higher rates of asthma, with research finding there is "consistent evidence" to suggest the asthma stems from the farms (Sigurdarson and Kline, 2006:129; 1486-91). Particulate matter and suspended dust emitted from manure, which are linked to incidences of asthma and bronchitis, can actually be absorbed by the body and can have systemic effects, such as decreased lung function and even cardiac arrest (Michigan DEQ Toxics Steering Group, 2006).
Considering the direct exposure of farm workers to the manure sites, they are especially at risk of developing acute and chronic bronchitis, chronic obstructive airways disease and interstitial lung disease. Research has found that occupational asthma, acute and chronic bronchitis and organic dust toxic syndrome can be as high as $30 \%$ in factory farm workers (Horrigan et al., 2002).

CAFOs are also a major contributor of greenhouse gases and therefore add to the rate of global warming. Massey and Ulmer found that, "Globally, livestock operations are responsible for approximately $18 \%$ of greenhouse gas production and over 7\% of U.S. greenhouse gas emissions" (Massey and Ulmer, 2008). The EPA adds that methane and nitrous oxide (emitted from manure) are " 23 and 300 times more potent as greenhouse gases than carbon dioxide, respectively." (USEPA, 2009:11). Greenhouse gases not only come from manure, but directly from the animals, as well. Ruminant livestock (cows, sheep, or goats) have a special stomach called a rumen that allows them to digest tough grains or plants and during that digestion process (called enteric fermentation) methane is produced. The CDC found the U.S. cattle industry to be one of the primary methane producers in the country (Hribar, 2010).

Ironically, while economic benefits are cited as a positive reason to have a CAFO in the area, quality of life and home values (near the factory farms) can decrease. Manure odors coming from the farms as well as the increased amount of insects attracted to the area were the primary reasons for lowered quality of life and property value (Schmalzried and Fallon, 2007).

A consequence of large-scale animal production is that CAFOs are breeding grounds for disease-spreading insects such as houseflies, stable flies and mosquitos. Houseflies breed directly in manure while other flies breed in decaying organic material. Manure lagoons have freestanding water in which mosquitos actively breed (Hribar, 2010). Considering how quickly and abundantly these insects can multiply, the potential for spread of disease by these vectors is incredibly high: Flies are attracted to and eat human food, potentially spreading microbes that can cause dysentery and diarrhea (Bowman et al., 2000) and mosquitos can potentially spread zoonotic diseases, such as West Nile virus, St. Louis encephalitis and equine encephalitis (Steeves and Williams, 2007).

\section{CAFO - Environmental Degradation: Land, Water and Food Shortages}

Emissions and spread of disease from CAFOs are not the only environmental considerations - the sheer space needed for these farms as well as the area needed to farm food for the animals is monumental. This concern is not a new one - back in 2007, Haan et al. (1997) reported that, "farm animals and animal production facilities cover one-third of the planet's land 
surface, using more than two-thirds of all available agricultural land including the land used to grow feed crops" (Haan et al. 1997:12).

Forty percent of the world's land surface is used for the purposes of feeding the world's population - and the vast majority of that land (about $30 \%$ of the word's total ice-free surface) - is used not to raise grains, fruits and vegetables that are directly fed to human beings, but for animals humans eventually eat (Walsh, 2013). Regarding grain alone, 1.3 billion tons are consumed by farm animals each year (Walsh, 2013). If you consider how many people could be fed, should that land be used to grow crops for human consumption, it is clear that a plant-based vegan diet can lead to less hunger and starvation, worldwide. Thusly, claims like "there is not enough land to grow food for everyone, if everyone becomes vegan" are inaccurate and false.

Brazil is one of the world's leading producers and exporters of beef and soy - and it's also home to the world's largest tracts of remaining tropical forest. In direct response to a combination of government policies, supply chain interventions and changes in market conditions, Amazon deforestation rates dropped by more than $80 \%$ between 2004 and 2014 (Arima et al., 2014; Gibbs et al., 2015a; Nepstad et al., 2006). However, even with this decline in deforestation, Brazil maintains one of the highest absolute rates of deforestation in the world. In 2014, nearly $5000 \mathrm{~km}^{2}$ were cleared in the Brazilian Amazon and expansion of cattle pastures continues to be a major cause of deforestation. Pasturelands now occupy at least $60 \%$ of cleared land in the Brazilian Amazon (Gibbs et al., 2015b). The Union of Concerned Scientists promotes lessening deforestation, by citing research from two research teams: Winrock International and Woods Hole Research Center. Using satellite imagery, ground-based inventories, mathematical models, these groups were about to calculate that tropical deforestation accounts for a direct increase in global warming pollution in the amount of 3.0 billion tons of carbon dioxide a year (UCS, 2013).

Not only does raising animals for consumption require significant land mass - it also requires vast amounts of water. One primary component of raising farm animals is the requirement of clean water both for the animals to directly consume as well as to grow the crops used as their food sources. Livestock production - which includes meat, milk and eggs — uses one-third of the world's fresh water. In a 2013 article, Time reported, "There may be no other single human activity that has a bigger impact on the planet than the raising of livestock" (Walsh, 2013). The impact of a lack of usable water is increasing; it's estimated that by 2020, 250 million people may experience water shortages, resulting in some countries' food production being cut in half (IPCC, 2007). The World Food Programme reports that currently 795 million people - one in nine - still go to bed on an empty stomach each night. Even more - one in three - suffer from some form of malnutrition (WFP, 2017).

Despite the strain on water availability and food availability, the FAO projects that meat and dairy production will be double from present levels in 2050 (primarily in the developing world) (Steinfeld et al., 2006). The risks associated with a lack of food and potable water extend into national security interests and peacekeeping endeavors, with the United Nations Secretary-General Ban Ki-moon noting that, "natural disasters, droughts and other changes brought about by global warming are likely to become a major driver of war and conflict" (UNNC, 2007).

Farming land-species for consumption is not the only issue: Environmentally-speaking, the acts of fishing and catching seafood are also quite negative. Overfishing has impacted much of the oceanic ecosystems. The United Nations Food and Agricultural Organization (FAO) found that in 2006, 110 million tons of fish were supplied for human consumption, with the top ten fishery-producer countries being: China, Peru, the United States, Indonesia, Japan, Chile, India, the Russian Federation, Thailand and Philippines. Additionally, "the maximum wild capture fisheries potential from the world's oceans has probably been reached," with $80 \%$ of the world's fish stocks "fully exploited or overexploited" therefore "requiring effective and precautionary management" (UNDPI, 2010:1).

"Overfishing can wreak havoc and destroy the environment and marine ecology and completely disrupt the food chain. For example, herring is a vital prey species for the cod. Therefore, when herring are overfished the cod population suffers as well. And this has a chain reaction on other species too. For example, seabirds such as puffins were dependent on the sandeel for their food around the Shetland Islands. However, with the overfishing of sandeels, the colonies of seabirds nesting around Shetland automatically declined. Therefore, it can be understood that if the food chain breaks at any level, it will have a domino effect on all living organisms in the chain" (Jetson, 2014).

Considering that sanctioned fishing has reached maximum capacity, unregulated and wrongly-caught species account for even greater impact on aquatic ecosystems. "Unwanted" by-catch species of fish/marine life have been found by the FAO to account for more than 20 million tons, or $23 \%$ of catches. Additionally, 11-26 million tons of catch are caught illegally and through unregulated fishing. The FAO and United Nations Environmental Programme (UNEP) further estimate that abandoned, lost or otherwise discarded fishing gear in the oceans make up approximately $10 \%$ (640,000 tons) of all marine litter (UNDPI, 2010). The 
amount of environmental destruction caused by fishing is truly staggering and unless positive steps are taken the oceanic ecosystems will surely fail.

The vast amount of environmental destruction occurring due to factory farming, fishing, etc, are not the only concerns which are leading to the promotion of veganism; the health concerns of these environmental impacts as well as the negative health impacts of consuming animal products are also coming to the forefront. In June of 2017, the American Medical Association (AMA) adopted a resolution for hospitals to not only provide plant-based meals but remove processed meats from menus. James Loomis, M.D., M.B.A., medical director of the Barnard Medical Center, stated, "Hospitals that provide and promote fruits, vegetables, whole grains and beans are likely to reduce readmissions, speed recovery times and measurably improve the long-term health of visitors, patients and staff' (PCRM, 2017). Furthermore, in response to promoting the health-benefits of plant-based meals, many school systems are offering vegan options for their students. In 2017, all New York City public schools will offer at least one vegan option, daily. And three NYC schools (PS1, PS244 and PS343) have transitioned to having allvegetarian menus. According to PS1 Principal Arlene Ramos, students are actually asking for healthier, meatless options and are loving what the school now provides. Moreover, Brooklyn Borough President, Eric L. Adams (who recently went vegan and reversed his type 2 diabetes) wholly supports the vegan meal options and said, "It is particularly exciting to learn that this is a youth-driven initiative." New York City isn't the only major cosmopolitan area to promote veganism in its school system - also in 2017 seven schools in the Los Angeles school district launched their own vegan pilot programs (OGP, 2017). The successes of these programs are likely to lead to the adoption of additional school districts following suit and adding vegan meals to their school lunches.

\section{Materials and Methods}

Our exploratory, empirical research utilized an online self-administered survey, $100 \%$ anonymous, that we designed and implemented on the Survey Monkey website. Basic general lifestyle questions were asked regarding shopping and food consumption habits, with answers in a multiple-choice format. Two core groups were sought, omnivores and vegans and we aimed for a minimum sample size of 75 of each. Convenience/purposive sampling was used for the omnivores and snowball sampling was used to obtain vegans. Since vegans are a relatively small subgroup in society and not easily found/identified, snowball/purposive sampling was used to seek out members in this group by sourcing individuals through social media communities as well as animal rescue organizations. We did not utilize the respondents within the Survey Monkey database as previous experience working in the private research sector has shown us that utilizing paid survey respondents can often result in rushed/inaccurate responses and lessen the validity of data. Further, since snowball/purposive sampling was used to obtain the vegan cohort in this study, we used a similar method (convenience/purposive) to obtain omnivores to ensure greater validity in comparing the two sample groups.

To qualify for the study, respondents had to meet the following requirements:

- Live in one geographical area: New Jersey and New York

- Minimum of 18 years old

We used the aforementioned geographic area due to convenience as well as the high population and diversity existing in this area.

The survey was launched March 6, 2017 for omnivores and March 13, 2017 for vegans; the link was closed out on March 23, 2017 after the target sample size in both groups had completed the survey.

Demographically, the samples are fairly balanced regarding respondents' gender, educational level and age. Data was then cleaned to remove anyone who did not complete the survey after starting it and those who lived out of the target geographical area. SPSS-23 was used for data analysis.

In regards to validation and reliability testing, our exploratory study sought to be as valid as possible given the constraints of having to rely upon convenience and snowball sampling. However, given our sample base sizes and use of significance-testing using SPSS, we are confident in the ability to replicate results on a larger scale. Moreover, the use of utilizing anonymous sampling methods ensures for greater honesty in responses as well as a greater likelihood of completion by respondents. Furthermore, a pre-test amongst five individuals concluded the questionnaire was easy to understand and all answer choices were exhaustive and complete. All surveys were completed within a fairly short time frame (roughly two weeks) and used the same exact questionnaire, which further leads to validity of our exploratory study.

\section{Results}

Vegans have or are planning on having significantly fewer children than omnivores, with 4-in-10 indicating they will not have any children (Tables 1 and 2).

While the majority of omnivores and vegans indicate they recycle everything they can at home, two- 
thirds of vegans indicate specifically looking for products in recyclable packing at the point of purchase - this is significantly more than omnivores, two-thirds of whom indicate they don't care about a product's packaging (Tables 3-6).

Omnivores were split, with $45 \%$ indicating they would likely consistently purchase vegan options and $55 \%$ indicating they would not. (Tables 7 and 8 )

Omnivores indicate that dairy is consumed by half the sample on a daily basis, along with meat eaten daily by $42.5 \%$ of the sample. Nearly $70 \%$ of omnivores rarely/never consume non-dairy products, whereas significantly more vegans $(9$-in-10) consume non-dairy products on a daily/weekly basis (Tables 9-11).

Omnivores indicate greatest likelihood of becoming vegan if: Legitimate reports showed animals on factory farms were unhealthy, legitimate reports showed animals on factory farms were abused and if their personal physician told them becoming vegan would make them healthier. Moreover, while omnivores indicate influence towards veganism if their personal physician claims veganism is healthy, $11 \%$ fewer respondents have as much faith in academic research making a similar claim. Environmental concerns were the least influential cause to influence an omnivore towards veganism followed by the impact of someone's spouse/partner/significant other being vegan (Table 12). Our data, therefore, is supporting the symbolic change (i.e., symbolic interactionism) that the consumption of animals is no longer being viewed as necessary for survival.

Table 1: Crosstab: Number of children by dietary plan

\begin{tabular}{|c|c|c|c|c|}
\hline \multirow{2}{*}{\multicolumn{2}{|c|}{$\begin{array}{l}\text { Q. How many children do you have } \\
\text { or realistically plan on having? }\end{array}$}} & \multicolumn{3}{|c|}{ Dietary plan } \\
\hline & & \multirow{2}{*}{$\begin{array}{l}\text { Omnivore } \\
17.0\end{array}$} & \multirow{2}{*}{$\begin{array}{l}\text { Vegan } \\
30.0\end{array}$} & \multirow{2}{*}{$\begin{array}{c}\text { Total } \\
47.0\end{array}$} \\
\hline None & Count & & & \\
\hline & $\%$ Within dietary plan & $24.6 \%$ & $43.5 \%$ & $34.1 \%$ \\
\hline \multirow[t]{2}{*}{1} & Count & 12.0 & 14.0 & 26.0 \\
\hline & $\%$ Within dietary plan & $17.4 \%$ & $20.3 \%$ & $18.8 \%$ \\
\hline \multirow[t]{2}{*}{$2-3$} & Count & 37.0 & 25.0 & 62.0 \\
\hline & $\%$ Within dietary plan & $53.6 \%$ & $36.2 \%$ & $44.9 \%$ \\
\hline \multirow[t]{2}{*}{4 or more } & Count & 3.0 & 0.0 & 3.0 \\
\hline & $\%$ Within dietary plan & $4.3 \%$ & $0.0 \%$ & $2.2 \%$ \\
\hline \multirow[t]{2}{*}{ Total } & Count & 69.0 & 69.0 & 138.0 \\
\hline & $\%$ Within dietary plan & $100.0 \%$ & $100.0 \%$ & $100.0 \%$ \\
\hline
\end{tabular}

Table 2: Chi-square tests: Number of children by dietary plan

\begin{tabular}{lcll}
\hline & Value & df & Asymptotic significance (2-sided) \\
\hline Pearson chi-square & $9.072^{\mathrm{a}}$ & 3 & 0.028 \\
Likelihood ratio & 10.293 & 3 & 0.016 \\
N of valid cases & 138.000 & & \\
\hline
\end{tabular}

a. 2 cells $(25.0 \%)$ have expected count less than 5

The minimum expected count is 1.50

Table 3: Crosstab: Tendency to recycle by dietary plan

\begin{tabular}{|c|c|c|c|c|}
\hline \multirow{2}{*}{\multicolumn{2}{|c|}{ Q. How often do you recycle at home? }} & \multicolumn{3}{|c|}{ Dietary Plan } \\
\hline & & \multirow{2}{*}{$\frac{\text { Omnivore }}{48.0}$} & \multirow{2}{*}{$\begin{array}{c}\text { Vegan } \\
55.0\end{array}$} & \multirow{2}{*}{$\begin{array}{c}\text { Total } \\
103.0\end{array}$} \\
\hline I recycle everything I can & Count & & & \\
\hline & $\%$ Within dietary plan & $69.6 \%$ & $79.7 \%$ & $74.6 \%$ \\
\hline \multirow[t]{2}{*}{ I recycle about $2 / 3$ of what I can } & Count & 11.0 & 6.0 & 17.0 \\
\hline & \% Within dietary plan & $15.9 \%$ & $8.7 \%$ & $12.3 \%$ \\
\hline \multirow[t]{2}{*}{ I recycle about $1 / 3$ of what I can } & Count & 5.0 & 6.0 & 11.0 \\
\hline & \% Within dietary plan & $7.2 \%$ & $8.7 \%$ & $8.0 \%$ \\
\hline Recycling is available where & Count & 3.0 & 1.0 & 4.0 \\
\hline I live, but I do not recycle & \% Within dietary plan & $4.3 \%$ & $1.4 \%$ & $2.9 \%$ \\
\hline It is not available where I live, & Count & 2.0 & 1.0 & 3.0 \\
\hline so I do not recycle at home & $\%$ Within dietary plan & $2.9 \%$ & $1.4 \%$ & $2.2 \%$ \\
\hline \multirow[t]{2}{*}{ Total } & Count & 69.0 & 69.0 & 138.0 \\
\hline & $\%$ Within dietary plan & $100.0 \%$ & $100.0 \%$ & $100.0 \%$ \\
\hline
\end{tabular}


Table 4: Chi-square tests: Tendency to recycle by dietary plan

\begin{tabular}{lrll}
\hline & Value & df & Asymptotic Significance (2-sided) \\
\hline Pearson chi-square & $3.371^{\mathrm{a}}$ & 4 & 0.498 \\
Likelihood ratio & 3.446 & 4 & 0.486 \\
$\mathrm{~N}$ of valid cases & 138.000 & & \\
\hline
\end{tabular}

a. 4 cells $(40.0 \%)$ have expected count less than 5

The minimum expected count is 1.50

Table 5: Crosstab: Tendency to purchase recyclable packages by dietary plan

Q. When purchasing something, does its packaging impact how likely you are to buy it?

I only buy things with recyclable packaging

I always try to buy something

with recyclable packaging

I usually try to buy something

with recyclable packaging

No, I buy the product for the product

and don't care what it's packaged in

Total

Count
\% Within dietary plan
Count
\% Within dietary plan
Count
\% Within dietary plan
Count
\% Within dietary plan
Count
\% Within dietary plan

\section{Dietary plan}

\begin{tabular}{ccc}
\hline Omnivore & Vegan & Total \\
\hline 0.0 & 1.0 & 1.0 \\
$0.0 \%$ & $1.4 \%$ & $0.7 \%$ \\
1.0 & 19.0 & 20.0 \\
$1.4 \%$ & $27.5 \%$ & $14.5 \%$ \\
14.0 & 32.0 & 46.0 \\
$20.3 \%$ & $46.4 \%$ & $33.3 \%$ \\
54.0 & 17.0 & 71.0 \\
$78.3 \%$ & $24.6 \%$ & $51.4 \%$ \\
69.0 & 69.0 & 138.0 \\
$100.0 \%$ & $100.0 \%$ & $100.0 \%$ \\
\hline
\end{tabular}

Table 6: Chi-square tests: Tendency to purchase recyclable packages by dietary plan

\begin{tabular}{llll}
\hline & Value & df & Asymptotic Significance (2-sided) \\
\hline Pearson chi-square & $43.525^{\text {a }}$ & 3 & 0.000 \\
Likelihood ratio & 48.673 & 3 & 0.000 \\
N of valid cases & 138.000 & & \\
\hline
\end{tabular}

a. 2 cells $(25.0 \%)$ have expected count less than 5

The minimum expected count is 0.50

Table 7: Crosstab: Likelihood of purchasing vegan options by dietary plan

\begin{tabular}{|c|c|c|c|c|}
\hline \multirow{2}{*}{\multicolumn{2}{|c|}{$\begin{array}{l}\text { Q. Vegan meals have no meat, eggs or } \\
\text { dairy in them. If great-tasting, healthy and } \\
\text { well-priced vegan food options/meals } \\
\text { were always available to you, would } \\
\text { you consistently choose them? }\end{array}$}} & \multicolumn{3}{|c|}{ Dietary plan } \\
\hline & & \multirow{2}{*}{$\begin{array}{l}\text { Omnivore } \\
12\end{array}$} & \multirow{2}{*}{$\begin{array}{l}\text { Vegan } \\
69\end{array}$} & \multirow{2}{*}{$\begin{array}{l}\text { Total } \\
81\end{array}$} \\
\hline Definitely yes & Count & & & \\
\hline & $\%$ Within dietary plan & $17.4 \%$ & $100.0 \%$ & $58.7 \%$ \\
\hline \multirow[t]{2}{*}{ Probably yes } & Count & 19.0 & 0.0 & 19.0 \\
\hline & $\%$ Within dietary plan & $27.5 \%$ & $0.0 \%$ & $13.8 \%$ \\
\hline \multirow[t]{2}{*}{ Probably not } & Count & 29.0 & 0.0 & 29.0 \\
\hline & $\%$ Within dietary plan & $42.0 \%$ & $0.0 \%$ & $21.0 \%$ \\
\hline \multirow[t]{2}{*}{ Definitely not } & Count & 9.0 & 0.0 & 9.0 \\
\hline & $\%$ Within dietary plan & $13.0 \%$ & $0.0 \%$ & $6.5 \%$ \\
\hline \multirow[t]{2}{*}{ Total } & Count & 69.0 & 69.0 & 138.0 \\
\hline & $\%$ Within dietary plan & $100.0 \%$ & $100.0 \%$ & $100.0 \%$ \\
\hline
\end{tabular}

Table 8: Chi-square tests: Likelihood of purchasing vegan options by dietary plan

\begin{tabular}{llll}
\hline & Value & $\mathrm{df}$ & Asymptotic Significance (2-sided) \\
\hline Pearson chi-square & $97.111^{\mathrm{a}}$ & 3 & 0.000 \\
Likelihood ratio & 123.352 & 3 & 0.000 \\
$\mathrm{~N}$ of valid cases & 138.000 & & \\
\hline
\end{tabular}

a. 2 cells $(25.0 \%)$ have expected count less than 5 .

The minimum expected count is 4.50 . 
Jennifer M. Ghahari and Jennifer A. McAdam / Journal of Social Sciences 2018, Volume 14: 1.11 DOI: $10.3844 /$ jssp.2018.1.11

Table 9: Frequency of consumption five food types by omnivores

\begin{tabular}{|c|c|c|c|c|c|c|}
\hline & & Meat & Seafood & Eggs & Dairy & Non-dairy \\
\hline Daily & Count & 31.0 & 2.0 & 14.0 & 37.0 & 11.00 \\
\hline Weekly & $\%$ & $44.90 \%$ & $2.90 \%$ & $20.30 \%$ & $53.60 \%$ & $15.90 \%$ \\
\hline Rarely & Count & 33.0 & 32.0 & 42.0 & 23.0 & 12.00 \\
\hline \multirow[t]{5}{*}{ Never } & $\%$ & $47.80 \%$ & $46.40 \%$ & $60.90 \%$ & $33.30 \%$ & $17.40 \%$ \\
\hline & Count & 5.0 & 26.0 & 11.0 & 6.0 & 26.00 \\
\hline & $\%$ & $7.20 \%$ & $37.70 \%$ & $15.90 \%$ & $8.70 \%$ & $37.70 \%$ \\
\hline & Count & 0.0 & 9.0 & 2.0 & 2.0 & 20.00 \\
\hline & $\%$ & $0.00 \%$ & $13.00 \%$ & $2.90 \%$ & $2.90 \%$ & $29.00 \%$ \\
\hline
\end{tabular}

Q. On average, how often do you eat the following (either by itself or as an ingredient in something):

- Meat (like beef, lamb, pork, chicken, etc.)

- Fish or other Seafood (like shrimp, crab, mussels, etc.)

- Eggs

- Dairy (like regular milk or cheese)

- Non-Dairy Milks or Cheeses (like almond milk, soy milk, etc.)

Table 10: Crosstab: Non-dairy consumption frequency by dietary plan

\begin{tabular}{|c|c|c|c|c|}
\hline & & \multicolumn{3}{|c|}{ Dietary plan } \\
\hline & & Omnivore & Vegan & Total \\
\hline \multirow[t]{2}{*}{ Daily } & Count & 11.00 & 46.00 & 57.00 \\
\hline & $\%$ Within dietary plan & $15.9 \%$ & $66.7 \%$ & $41.3 \%$ \\
\hline \multirow[t]{2}{*}{ Weekly } & Count & 12.00 & 17.00 & 29.00 \\
\hline & $\%$ Within dietary plan & $17.4 \%$ & $24.6 \%$ & $21.0 \%$ \\
\hline \multirow[t]{2}{*}{ Rarely } & Count & 26.00 & 3.00 & 29.00 \\
\hline & $\%$ Within dietary plan & $37.7 \%$ & $4.3 \%$ & $21.0 \%$ \\
\hline \multirow[t]{2}{*}{ Never } & Count & 20.00 & 3.00 & 23.00 \\
\hline & $\%$ Within dietary plan & $29.0 \%$ & $4.3 \%$ & $16.7 \%$ \\
\hline \multirow[t]{2}{*}{ Total } & Count & 69.00 & 69.00 & 138.00 \\
\hline & $\%$ Within dietary plan & $100.0 \%$ & $100.0 \%$ & $100.0 \%$ \\
\hline
\end{tabular}

Table 11: Chi-square tests: Non-dairy consumption frequency by dietary plan

\begin{tabular}{lccc}
\hline & Value & df & Asymptotic Significance (2-sided) \\
\hline Pearson chi-square & $53.160^{\mathrm{a}}$ & 3 & 0.000 \\
Likelihood ratio & 58.951 & 3 & 0.000 \\
N of valid cases & 138.000 & & \\
\hline
\end{tabular}

a. 0 cells $(0.0 \%)$ have expected count less than 5

The minimum expected count is 11.50

Table 12: Factors influencing omnivores to consider veganism

\begin{tabular}{|c|c|c|c|c|c|c|c|}
\hline & & $\begin{array}{l}\text { Academic research } \\
\text { show Veganism } \\
\text { help environment }\end{array}$ & $\begin{array}{l}\text { Academic research } \\
\text { show veganism } \\
\text { Healthier }\end{array}$ & $\begin{array}{l}\text { Personal doctor } \\
\text { says veganism } \\
\text { healthier }\end{array}$ & $\begin{array}{l}\text { Spouse/sig. } \\
\text { other is } \\
\text { vegan }\end{array}$ & $\begin{array}{l}\text { Legitimate reports } \\
\text { of physical } \\
\text { abuse of factory } \\
\text { farm animals }\end{array}$ & $\begin{array}{l}\text { Legitimate } \\
\text { reports show } \\
\text { factory farm } \\
\text { animals unhealthy }\end{array}$ \\
\hline Much more & Count & 9.00 & 18.00 & 26.00 & 24.00 & 24.00 & 26.00 \\
\hline Likely & $\%$ & $13.00 \%$ & $26.10 \%$ & $37.70 \%$ & $34.80 \%$ & $34.80 \%$ & $37.70 \%$ \\
\hline Slightly more & Count & 37.00 & 31.00 & 29.00 & 22.00 & 34.00 & 33.00 \\
\hline likely & $\%$ & $53.60 \%$ & $44.90 \%$ & $42.00 \%$ & $31.90 \%$ & $49.30 \%$ & $47.80 \%$ \\
\hline \multirow[t]{2}{*}{ No effect } & Count & 22.00 & 18.00 & 13.00 & 22.00 & 10.00 & 9.00 \\
\hline & $\%$ & $31.90 \%$ & $26.10 \%$ & $18.80 \%$ & $31.90 \%$ & $14.50 \%$ & $13.00 \%$ \\
\hline
\end{tabular}

Q. How much would each of the following make you more-likely to follow a Vegan lifestyle:

- If legitimate academic research says becoming Vegan would significantly help the environment

- If legitimate academic research says becoming Vegan would make you significantly healthier

- If your personal doctor/physician tells you becoming Vegan will make you significantly healthier

- If your spouse/partner/significant other is Vegan

- If legitimate reports show physical abuses of animals on factory farms

- If legitimate reports show animals on factory farms are very unhealthy 


\section{Discussion}

Our research clearly indicates socio-behavioral differences between omnivores and vegans living in New Jersey and New York. Not only do these differences exist, but our study has discovered possible ways to impact societal change and increase adherence of the vegan lifestyle among omnivores.

In terms of environmentally-related behavioral aspects, omnivores and vegans in our sample present significantly differently. Considering the rate of Earth's population increase, vegans appear more environmentally-conscious in terms of reducing population growth, with 4-in-10 indicating they do not plan to have any children, compared to $25 \%$ of omnivores who feel similarly. Additionally, nearly $60 \%$ of omnivores plan to have two or more children, compared to just $36 \%$ of vegans who indicate similarly. Considering the rate of global population increase, along with the concern of dwindling resources and land mass necessary to feed such a population, negative population growth is clearly more sustainable.

Recycling is another area where omnivores and vegans differ in behavior. While there is no significant difference among the two cohort samples (70\% and $80 \%$, respectively, indicate they recycle everything they can at home), there is a strong differentiation among products purchased. $76.7 \%$ of omnivores (compared to $24.6 \%$ of vegans) indicate they do not care what a product is packaged in and only buy something based on its product. Conversely, nearly 3 -in-10 of vegans specifically look for recyclable packaging when shopping (only/always trying to buy things with recyclable packaging). Nearly half of vegans indicate "usually trying" to purchase things with recyclable packaging. Therefore, while the majority of omnivores and vegans both try to recycle everything they can at home, since vegans are apt to purchase more products in recyclable packaging, this cohort is making a more positive environmental impact regarding recycling.

As our literature review shows, an omnivore diet is wholly detrimental to the environment in a number of ways. These detrimental environmental impacts include CAFOs' greenhouse gas emissions (contributing to climate change) and pathogen-exposure spread. Further, a result of farmed animals' much needed grazing land is the destruction/deforestation of tropical rainforests and other land area. The vast amount of fresh/potable water needed for CAFO animals causes a drain on a valued and limited resource. Finally, the exploitation/over-capture of fish at unsustainable levels poses a threat to the delicate natural balance of the food chain. All of these factors, which are necessary to accommodate an omnivore lifestyle, negatively impact global sustainability.

Our research found that $45 \%$ of omnivores are likely to consistently choose vegan options if these foods were great tasting, healthy, well-priced and always available. Only $12.3 \%$ of omnivores said they definitely would not consistently choose vegan options in this scenario. Therefore, a positive environmental impact can be made simply by making vegan options more readily available in society. With $87.6 \%$ of omnivores reporting they consume dairy products on a daily or weekly basis, the positive environmental impact to be made simply by switching to non-dairy products is monumental. This can be refuted, however, as non-dairy options are widely available and yet only $31.5 \%$ of omnivores claim to consume this category daily or weekly; $39.7 \%$ indicate "rarely" and $28.8 \%$ indicate they "never" consume non-dairy products.

These changes in behavior are evidence of a shifting culture, supporting the theory of symbolic interactionism. Our research and literature review show that there has been movement away from viewing animals as a necessary food source, critical for human survival. The growth of animal activism and environmental movements have marked a change in how animals are viewed and their innate value to society. The ubiquitous quality of social media has allowed for vegans to promote the benefits of vegan lifestyle: Animal and environmental protection and better health; thereby reaching many millions of people and prompting a discussion about the role of animals as a food source in the $21^{\text {st }}$ century. Thus, the very nature of our understanding of animals has entered the discussion and altered perceptions. Animals are no longer thought of as simply "things" to be mastered and, frequently, eaten; they are no longer simply byproducts of human leisure and gluttony. Rather, the paradigm is shifting to viewing animals as an integral force in our environment's sustainability and as sentient living creatures deserving of protection and compassion.

Aside from product availability, we sought to find what specific factors would influence omnivores to consider following a vegan lifestyle. Omnivores indicate greatest likelihood of becoming vegan if their personal health is affected; primarily if: Legitimate reports showed animals on CAFOs were unhealthy and if their physician told them becoming vegan would make them, personally, healthier. However, while omnivores indicate influence towards veganism if their personal physician claims veganism is healthy, $11 \%$ fewer respondents have as much faith in academic research making a similar claim. Additionally, omnivores reported similarly high influence in becoming vegan if legitimate reports showed animals on factory farms were abused. While concern for the welfare of animals on factory farms is likely the driving factor in this category, one must also consider that omnivores selecting this option are likely to also think abused animals are, rightly so, unhealthy to consume. The impact of an omnivore's spouse/partner/significant other being vegan was found to be the second least influential factor in our study; however, if an omnivore 
is in a long-term relationship or married to another omnivore, then it's possible they answered accordingly (i.e. that the dietary plan of their partner is inconsequential.) Ironically, while the focus of our study is examining veganism and the environment, "legitimate academic research saying veganism would significantly help the environment" was the least influential factor to impact whether or not an omnivore would consider veganism.

\section{Conclusion}

It would appear that while many omnivores in our study are open to becoming vegan or at least consuming vegan options more often, the way to lead to less meat/dairy/seafood consumption in society is to make vegan options more readily available as well as to further spread the knowledge of conditions of animals on factory farms and the level to which an omnivore diet is unhealthy. Policy makers, environmental scientists and educators can utilize the findings in this research as a means to further supplement and promote ways to combat climate change. As vegan social media websites, campaigns and postings (especially by famous public figures) spread the health, environmental and ethical benefits of a vegan lifestyle, the spread of veganism is likely to increase - particularly amongst teens and young adults. Furthermore, as public policy leaders become vegan and promote the impacts made to their own health, they are likely to promote a more veganfriendly community in which they preside over (as noted with the cited example in NYC.) Moreover, as groups like the AMA call for vegan meals to be made available at hospitals, citing the many health benefits associated with such, more of society will be exposed to these types of meals and made aware of their many health benefits and associate the correlation between veganism with being healthy. As social institutions such as schools, hospitals and even prisons adopt offering and adhering to vegan meal plans and some restaurants are utilizing campaigns such as "Meatless Mondays", more of society will be exposed to this style of eating, making it less foreign and more mainstream. Furthermore, as the younger generations in society become more open and accepting (and infavor of) a vegan diet, this will propel an overall societal shift towards a vegan movement. It is through these measures that veganism can be promoted and in which a positive environmental impact of increased sustainability and reduced climate change can be achieved.

\section{Acknowledgement}

Jennifer M. Ghahari wishes to thank Professors Kathleen Korgen, Vincent Parrillo and Lance Risley for their invaluable friendship, guidance and support.
Jennifer A. McAdam wishes to thank Dr. Rosanne Martorella for her invaluable support and direction and Dr. Emily H. Mahon for her insight and encouragement.

\section{Funding Information}

The authors received no funding for this manuscript.

\section{Author Contributions}

Jennifer M. Ghahari: Developed survey, conducted data analysis and contributed to writing the manuscript.

Jennifer A. McAdam: Assisted with survey development, contributed to writing the manuscript and proofed/edited the manuscript.

\section{Ethics}

This article is original and contains unpublished material. The corresponding author confirms that all of the other authors have read and approved the manuscript and there are no ethical issues involved.

\section{References}

Arima, E.Y., P. Barreto, E. Araujo and B. Soares-Filho, 2014. Public policies can reduce tropical deforestation: Lessons and challenges from Brazil. Land Use Policy 41: 465-73.

Bowman, A., K.J. Mueller and M. Smith, 2000. Increased animal waste production from Concentrated Animal Feeding Operations (CAFOs): Potential implications for public and environmental health. Nebraska Center for Rural Health Research, University of Nebraska Medical Center, Department of Preventative Societal Medicine.

Burkholder, J., B. Libra, P. Weyer, S. Heathcote and D. Kolpin et al., 2007. Impacts of waste from concentrated animal feeding operations on water quality. Environ. Health Perspectives, 11: 308-312.

Burns, R.T., H. Xin, R. Gates, H. Li and S.J. Hoff et al., 2007. Tyson broiler ammonia emission monitoring project: Final report. Agricultural and Biosystems Engineering Technical Reports and White Papers 15.

Gibbs, H.K., L. Rausch, J. Munger, I. Schelly and D.C. Morton et al., 2015a. Brazil's soy moratorium. Science, 347: 6220: 377-378.

Gibbs, H.K., J. Munger, J. L'Roe, P. Barreto and R. Pereira et al., 2015b. Did ranchers and slaughterhouses respond to zero-deforestation agreements in the Brazilian Amazon? Conservation Lett., 9: 32-42. DOI: 10.1111/conl.12175

Haan C., H. Steinfeld and H. Blackburn, 1997. Livestock and the Environment: Finding a Balance. 1st Edn., European Commission Directorate-General for Development, Brussels. 
Horrigan, L., R.S. Lawrence and P. Walker, 2002. How sustainable agriculture can address the environmental and human health harms of industrial agriculture. Environ. Health Perspectives, 110: 445-56.

Hribar, C., 2010. Understanding concentrated animal feeding operations and their impact on communities. National Association of Local Boards of Health.

IVU, 1985. Memorandum of association and articles of association. International Vegetarian Union.

IPCC, 2007. Climate Change Impacts, Adaptation and Vulnerability.

Jetson, K., 2014. Impact of overfishing on human lives. Marine Sci. Today.

MacDonald, J.M. and W.D. McBride, 2009. The transformation of U.S. livestock agriculture: Scale, efficiency and risks. United States Department Agriculture.

Massey, R. and A. Ulmer, 2008. Agriculture and greenhouse gas emissions. Agriculture and Greenhouse Gas Emissions University of Missouri Extension.

McArdle, J., 1991. Humans are omnivores. Vegetarian Resource Group.

Michigan DEQ Toxics Steering Group, 2006. CAFOschemicals associated with air emissions.

Nepstad, D.C., C.M. Stickler and O.T. Almeida, 2006. Globalization of the Amazon soy and beef industries: Opportunities for conservation. Conservation Biol., 20: 1595-603.

Paer, H.W., 1999. Cultural eutrophication of shallow coastal waters: Coupling changing anthropogenic nutrient inputs to regional management approaches.

OGP, 2017. Yes! 1,200 NYC public schools are adding a vegan lunch option to their menus. Green Planet.

PCIAFP, 2009. Putting meat on the table: Industrial farm animal production in America. Pew Commission Indus. Anim. Farm Product.

PCRM, 2017. News Release. "AMA passes resolution: Hospitals should provide plant-based meals and remove cancer-causing processed meats. Physicians Committee Responsible Med.

Rogers, S. and J. Haines, 2017. US environmental protection agency. Land remediation and pollution control division. National risk management research laboratory. Office of research and development. "Detecting and mitigating the environmental impact of fecal pathogens originating from confined animal feeding operations: Review.
Schmalzried, H.D. and L.F. Fallon, 2007. Large-scale dairy operations: Assessing concerns of neighbors about quality-of-life issues. J. Dairy Sci., 90: 2047-51.

Sigurdarson, S.T. and J.N. Kline, 2006. School proximity to concentrated animal feeding operations and prevalence of asthma in students. Chest, 129: 1486-91.

Spellman, F.R. and N.E. Whiting, 2007. Environmental Management of Concentrated Animal Feeding Operations (CAFOs). 1st Edn., CRC Press, Boca Raton, ISBN-10: 1420006533, pp: 496.

Steeves, S. and R. Williams, 2007. Contained animal feeding operations-insect considerations. Purdue Extension.

Steinfeld, H., P. Gerber, T. Wassenaar, V. Castel and M. Rosales et al., 2006. Livestock's long shadow. Food Agric. Organization United Nations.

TA, 2017. Veganism about More than what You Eat. Argus.

UCS, 2013. Measuring the role of deforestation in global warming. Union Concerned Scientists.

UNDPI, 2010. Resumed review conference on the agreement relating to the conservation and management of straddling fish stocks and highly migratory fish stock.

UNFAO, 2006. United Nations: Livestock a Major Threat to Environment. New York, United Nations.

UNFAO, 2012. World Agriculture Towards 2030/2050: the 2012 revision. Food and Agricultural Organization of United Nations.

UNNC, 2007. Ban Ki-moon calls on new generation to take better care of planet earth than his own. United Nations News Centre.

USBC, 2017. US and World Population Clock.

USCRS, 2010. Animal Waste and Water Quality: EPA Regulation of Concentrated Animal Feeding Operations (CAFOs).

USEPA, 2009. The quality of our nation's water. US Environ. Protection Agency.

U.S. GAO, 2008. Concentrated animal feeding operations: EPA needs more information and a clearly defined strategy to protect air and water quality from pollutants of concern.

Walsh, B., 2013. The triple whopper environmental impact of global meat production. Time.

WFP, 2017. World food programme. WFP. 